\title{
Patient involvement in surgical care-Healthcare personnel views and behaviour regarding patient involvement
}

Asa Andersson, Mattias Vilhelmsson, Victoria Fomichov Casaballe, Anna Lindhoff Larsson, Bergthor Björnsson, Per Sandström and Jenny Drott

The self-archived postprint version of this journal article is available at Linköping University Institutional Repository (DiVA):

http://urn.kb.se/resolve?urn=urn:nbn:se:liu:diva-163708

N.B.: When citing this work, cite the original publication.

Andersson, A., Vilhelmsson, M., Fomichov Casaballe, V., Lindhoff Larsson, A., Björnsson, B., Sandström, P., Drott, J., (2020), Patient involvement in surgical care-Healthcare personnel views and behaviour regarding patient involvement, Scandinavian Journal of Caring Sciences.

https://doi.org/10.1111/scs.12823

Original publication available at:

https://doi.org/10.1111/scs.12823

Copyright: Wiley (12 months)

http://eu.wiley.com/WileyCDA/ 


\title{
Patient involvement in surgical care- Health care personnel views and behaviour regarding patient involvement
}

\begin{abstract}
Background: All professions in surgical care have a responsibility to include patients in their health care. By Swedish law, all care should be done in dialogue with the patient. The essential part of health care is the meeting between patient and health care professional. In the interaction, a decision can be made, and needs can be identified to a safer care. Previous studies on patient participation have focussed on patients' perspectives in surgical care, but there is a paucity of studies about the personnel's perspective of estimated patient involvement in surgical care.

Aim: The aim of this study was to identify and describe health care personnel's view and behaviour regarding patient involvement in surgical care.

Method: A quantitative study with various professions was conducted. A validated questionnaire was used, remaining questions grouped under following areas: patient involvement, acute phase, hospital time, discharge phase and questions on employment and workplace.

Results: A total of 140 questionnaires were sent out to a surgical clinic in Sweden, and 102 questionnaires were answered. All professionals stated that clear information is an important part of patient involvement in surgical care. Statistically significant differences existed between the professions in the subscale information. Physicians rated their information higher than the registered nurses $(p=0.005)$ and the practical nurses did $(p=0.001)$. Hindrances to involving patients were lack of time and other priority tasks.
\end{abstract}


Conclusions: Professionals in surgical care graded information to be the most important thing for patient involvement. Participation in important decisions, including the possibility to express personal views and ask questions, are important factors for patient involvement. Barriers against patient involvement are lack of time and prioritization of other work activities.

KEYWORDS: information, surgical care, patient involvement, personnel's perspective, teamwork

\section{INTRODUCTION}

All professions in surgical care have a responsibility to involve their patients in their care. By Swedish law, all care should be done in consultation with the patient, and the patient's own opinions and questions should be taken into consideration. Human rights mean the right to be respected as a human being, and human rights also apply in health care (1). The core of health care is the meeting between the patient and the health care professional. In the interaction between patient and health care professional, decisions can be made, and needs can be identified. Patient involvement/participation is characterized as a relationship between patient and health care professionals. Over time, patients have become more active in their own care. Mutual interaction between patient and health care professionals is essential and an important component in achieving patient participation. The patient needs to be able to participate in the decisions made and have an active part in the treatment of symptoms and specific care (2-5).

Respecting and strengthening the patient are important characteristics of the health care professional (6). Patient participation can be related to aspects of care and decision-making, including self-care, education, and goal setting (7). Health care professionals should have a 
person-centred perspective, but they sometimes need support in performing person centeredness systematically and consistently. Documenting decisions is important to maintain continuity and partnership (8). Good care is achieved when health care professionals and patients agree on how care should be carried out. The partnership is also a central part of person-centred care and is based on trust between health professionals and patients.${ }^{9}$ By working in a person-centred way, care is improved. Person-centred care is the future, which is why decision-makers and management in health care must be willing to create models and support its implementation in health care $(10,11)$. Patient safety is not only affected by patient factors, such as age, sex/gender and occupation, but is also affected by encouragement and by obtaining information from caring staff $(12,13)$. There are obstacles to patients being active in their own care, which may include uncertainty in calling into question health professionals, difficulty having their requests for care honoured and being listened to. It can be challenging for health care professionals to respond to each individual patient. Patients who are more involved in their own care have increased feeling of safety (14). The challenge of creating good patient participation depends on the behaviour of health professionals. This means that non-supportive behaviour may be due to busy or stressedout health care professionals (15). Both staff and patients prefer a pleasant atmosphere and a mutual relationship based on trust, which has a positive effect on teamwork (16). Oxelmark et al. believe that through cooperation with the patient, nurses can try to respect how the patient looks at their situation (17). There are obstacles when the patient takes a passive role and there is a lack of teamwork between professions. Teamwork is hampered by the care staff talking in a language the patient does not understand (medical terms) or talking over the patient's head (17). Professionals who collaborate effectively with other members of other professions stimulate and facilitate teamwork (18). 
Surgical care is becoming increasingly advanced while care times are becoming shortened, and many surgical patients have advanced age and multiple morbidities. The working environment in surgical care can often be stressful, and there is currently a shortage of both health professionals and hospital beds. At the same time, health care professionals have a responsibility to involve the patient in their care. This places high demands on health care professionals in surgical care. A good interaction in the team reduces the risk of errors being committed, and patient safety can thus be increased. Patient safety has been shown to increase with higher patient participation; therefore, it would be important to examine the possibilities of what we could be done to involve the patient and get over the obstacles that exist. Previous studies on patient participation have focussed on patients' perspectives in surgical care, but there is a gap of knowledge on participation and surgical staff perspective.

\section{AIM}

The aim of the study was to identify and describe health care personnel's view and behaviour towards patient involvement in surgical care.

Research questions:

1. What does patient involvement of health care professionals mean in surgical care?

2. What is the health care personnel's view and behaviour regarding patient involvement, and what do health care professionals think hinder patient involvement? 


\section{METHOD}

\section{Design}

A quantitative cross-sectional study was carried out to answer the questions of the study. The study is a part of a larger project regarding patient involvement in surgical care, and earlier studies are published elsewhere $(19,20)$.

\section{Sample and data collection}

The inclusion criteria were physicians, registered nurses and practical nurses at a surgical clinic at a university hospital in southern Sweden, who were asked to participate and were recruited in spring 2018. The exclusion criteria were physiotherapists and temporary staff. Before the questionnaires were distributed, the staff was informed orally about the study at workplace meetings. The staff was also informed in writing through an information letter accompanying the questionnaire. Reminder e-mails were sent out in connection with the start of the study and when the data collection had been going on for a few weeks. The data collection was conducted in May 2018.

\section{Questionnaire}

A validated questionnaire was used in this study to describe the health care person's view and behaviour towards involvement in surgical care (21). The original questionnaire was developed to examine how the staff looked at the patient's participation during their time in hospital, during the acute phase, and on discharge and the ability of health care professionals to involve the patient in their care. The original questionnaire was designed in five phases. 
The first four phases were literature review, focus group discussions, construction of the issues and a pilot study. The final phase of the questionnaire construction was a main study conducted to establish the validity and reliability of the questionnaire. The final version of the questionnaire consisted of 57 questions. The first seven questions are on demographic issues with four response options. The remaining questions in the questionnaire are grouped under the following areas: patient involvement, acute phase, hospital time, discharge phase and questions on employment and workplace.

All questions in the questionnaire are answered on a 4-point Likert scale (22). The grading is "Not at all" (1) to "To a very great degree" (4) or "Don’t agree at all" (1) to "Agree completely" (4). The subscales of the questionnaire are patient involvement, information, patient needs, activity, motivation and hindrance. The questionnaire was reliability-tested by Arnetz et al. and showed a Cronbach's alpha value $>0.7$ (21). A reliability test of the internal consistency of the data in this study was conducted, which showed Cronbach's alpha over 0.7 , and in three of the subscales, Cronbach's alpha was $>0.8$.

\section{Statistical analysis}

Professional characteristics were summarized to compare differences between the three groups, and descriptive statistics were analysed. To test differences in the subscales between different professions, the non-parametric Kruskal-Wallis H test and ad hoc Mann-Whitney U test were used (23). The Kruskal-Wallis H differences among all professions were tested at the same time and when significant differences occurred, pairwise comparisons between the different professions were tested with the Mann-Whitney U test. The results of the Kruskal-Wallis H test are presented in a table in the results section, and the results of the Mann-Whitney U test are 
presented in the text. When analysing subscales, the results are presented as the median values. Since all subscales have different maximum values, these medians are presented as percentages. Fisher's exact test was used to perform pairwise comparisons between the different professions on the answers of individual questions. The questions have four possible answers, and those answers have been dichotomized before analysis. The threshold of statistical significance was set at $p<0.05$. The data in this study were handled in accordance with the authors' data processing of the questionnaire responses (21). Statistical analyses were conducted in IBM SPSS Statistics 25.

\section{ETHICAL APPROVAL}

The study has ethical approval from the regional ethics committee in Southeast Sweden (No: 2016/276-31). All staff who received the questionnaire were informed that participation was voluntary.

\section{RESULTS}

A total of 140 questionnaires were sent out, and 102 responded (response rate $73 \%$ ). There were similar response rates and internal missing data between the three included professional groups. Table 1 presents the characteristics of the questionnaire respondents. Most of the nurses were women, and most of the physicians were men. There was much variation in how long the professionals had worked in their workplace. The majority of physicians and assistant nurses had more than ten years of professional experience, and the nurses had less than half that. 
The response options were grouped into two categories, "fully aligned" or "fairly good" (positive factor) and "do not match" or "not at all" (negative factor). All participants stated that "patients receiving clear information" meant patient participation. "That the patient has primary responsibility for his or her future health" was graded lowest of the statements (Figure 1).

A strongly significant difference was seen between the professions in the subscale's information $(p=0.002)$ and motivation $(p=0.001)$. Significance was weaker in the subscale's activity $(p=$ $0.030)$ and hindrance $(p=0.030)$. In other subscales, we observed no significant differences between the professions. In all subscales, physicians graded higher than nurses. No significant difference was observed between the registered nurses and the practical nurses $(p=0.08)$. Statistically significant differences existed between the professions in the subscale information. Physicians rated their information to a greater extent than did the registered nurses $(p=0.005)$ and the practical nurses $(p=0.001)$. In the subscale motivation, where the issues focused on motivating and involving patients, there was a strongly significant difference between the physicians' estimation and that of the registered nurses $(p=0.006)$ or the practical nurses $(p=$ $0.001)$ (Table 2).

Table 3 presents the extent to which different professions informed patients about different activities. Providing information about physical activity was done to a large extent by all professions. Providing information about driving and sexual activity was done to a low degree. A minority of all participants informed patients about sexual activity. A majority of the physicians discussed returning to work with patients, unlike both nurse groups (Table 3). 
Table 4 shows the rates at which the health professionals believed they were prevented from being able to talk to and provide support to patients. The results show that the majority considered that lack of time and prioritization of other tasks hindered their provision of support to the patients. The practical nurses responded that the patient's own unwillingness was an obstacle to patient involvement more often than registered nurses and doctors did. A minority of doctors answered that their own insecurity was a hindering factor.

The results showed significant differences in patient aversion to involvement between the answers of doctors and practical nurses $(p=0.018)$ as well as between the answers of registered

nurses and practical nurses. There were also significant differences between doctors and practical nurses in the factor relatives $(p=0.003)$.

\section{DISCUSSION}

Health care professionals describe that they feel positively about patient involvement. Health care professionals surveyed consider clear information to be the most important factor for good patient involvement. Providing information and offering the possibility to ask questions align with the patients' wishes (19). Patients make their own important decisions in their care and express their own views and questions to health care professionals. Patient involvement increases the feeling of safety in patients $(24,25)$. Patients request increased involvement $(26,27)$, and so does nursing staff (16). To have continuous communication and information aims to meet the patient's needs (19). 
Other studies describe patients' perspectives, and patients think that the information they receive in some cases is lacking $(28,29)$. Clear information is important, but patients often want more information. This can be explained by the health care staff overestimating their own ability to provide information, as well as adapting the information for the patient (29). However, it may also be because patients do not understand the information the health care professional gives them, which may be due to difficulties in taking in information or the patient's lack of understanding of the medical language used by staff (30).

To discuss what the patient can and cannot do after a surgical procedure is important for an optimal recovery process. Sexual activity is not discussed in most cases. This is consistent with previous research conducted in surgical care, where patients have not discussed with health care professionals what they can do sexually and how the surgery affects them sexually. ${ }^{19}$ Health care professionals describe sexual activity as a complicated topic to talk about. Previous research shows that clearer guidelines are needed to discuss sexual activity with patients (31).

In health care, it is important to maintain a high level of patient involvement, not only because of the responsibility of the health workforce but also because it can contribute to increased patient safety (32). In this study, it was noted that health professionals saw several areas that were deficient in the involvement of patients. Health care professionals reported lack of time as the main reason for not giving the patients enough information. This is supported by previous research in which the time aspect affected not only patient involvement but also health care. By having less time, health care professionals feel restricted and cannot go through everything that they want with the patient. This means that some things are skipped or forgotten when they give their patients information (7). Due to tasks perceived to be of higher priority, there is not enough time to involve patients. Working actively to make patients involved in their 
own care is a new source of stress, both positive and negative. Developing routines in the workplace to involve patients in health care can help health care professionals reduce negative and increase positive effects of stress (33).

The demographic data in this study show that many of the professionals had more than 10 years of professional experience. Kolovos et al. stated that nurses with experience interact better with the patient than nurses with less than three years of experience (34). Less experienced nurses have more difficulty making the patient become involved (6). Individual care and ongoing information on treatment and the goals of health care create trust between patients and professionals and increases the patient's sense of involvement (20).

Professionals have knowledge of patient involvement, but there are obstacles to carrying it out and difficulties due to a lack of time and priority. Facilitating health care professionals and providing patients with support and guidelines for the involvement of patients is a problem that needs to be addressed at the management level. There is a willingness among health care managers to work on the patient perspective, but there is a lack of experience in patient involvement (35). In health care, patients meet practitioners of several professions. Ensuring that everyone in the team helps to involve the patient in the treatment and motivate the patient can lead to higher patient involvement. Continuous personalized information can contribute to increased patient participation (19), and the concept relies on three caring science concepts; learning, caring relationship and reciprocity (36). But it seemed to be a challenge how these could be achieved in the clinical practice. 


\section{Methodological considerations}

The present study contains both methodological strengths and weaknesses. The study used a questionnaire designed by Arnetz et al (21), contained 57 questions. A total Cronbach's alpha $>0.7$ (and in three of the subscales $>0.8$ ) is seen as a strength and a sign of high internal consistency. Because the study was conducted only in one clinic, this could have a negative impact on the external validity of the study results.

The results of this study are based on the questions in the questionnaire that aimed to address the study's purpose and research questions. The response rate was $73 \%$, which seen as a strength. However, it is also a limitation that we do not provide reasons for the non-responders who may not care about patient participation and might have biased the results. All the questions in the questionnaire were answered on a 4-point Likert scale, and the staff graded how well they agreed with each question. This type of survey and response options investigate attitudes and views. The scale used in this survey makes it possible to identify positive and negative responses. The questionnaire's grading was 4 points, which meant that a dichotomizing of positive and negative answers could be analysed and presented in the results.

The questionnaire contained six subscales: patient involvement, information, patient needs, activity, motivation and hindrances. All the subscales were relevant to the purpose of the study and are considered to strengthen the validity of the study. The questionnaire was made up of questions for which the respondents carried out a valuation. When valuation questions are used, the participants are likely to overestimate their ability. It is a strength that the three different professions responded to the questionnaire and that all groups were relatively evenly 
distributed in sample size. The sample included different sexes, ages and active work years, which can also be a study strength.

\section{CONCLUSION}

Health care professionals in surgical care rate the provision of clear information to the patients as the most important factor for patient involvement in their own care. Health care professionals think that patient participation in important decisions, given the opportunity to express their views and asking questions, are very important for patient involvement. Barriers for health care professionals to support patient participation are lack of time and prioritization of other work activities.

\section{CLINICAL IMPLICATIONS}

Health professionals have knowledge of patient involvement, but there are hindrances to it in clinical practice. Time constraints and other priorities can be common obstacles. Supporting health professionals and developing guidelines for improved patient involvement need to be created at the management level to create good conditions for stimulating patient involvement in surgical care. 


\section{REFERENCES}

1. WHO. A Declaration on the Promotion of Patient's Rights in Europé. Geneva: World Health Organization; 1994.

2. Cahill J. Patient participation: a concept analysis. J Adv Nurs 1996;24:561-571.

3. Castro EM, van Regenmortel T, Vanhaecht K, Sermeus W, van Hecke A. Patient empowerment, patient participation and patient-centeredness in hospital care: a concept analysis based on a literature review. Patient Educ Couns 2016;99:1923-1939.

4. Eldh AC, Ekman I, Ehnfors M. Conditions for patient participation and non-participation in health care. Nurs Ethics 2006;13:503-514.

5. Lin C, Cohen E, Livingston PM, Botti M. Perceptions of patient participation in symptom management: a qualitative study with cancer patients, doctors, and nurses. $J$ Adv Nurs $2019 ; 75: 412-422$.

6. Tobiano G, Bucknall T, Marshall A, Guinane J, Chaboyer W. Nurses' views of patient participation in nursing care. J Adv Nurs 2015;71:2741-2752.

7. Longtin Y, Sax H, Leape LL, Sheridan SE, Donaldson L, Pittet D. Patient participation: current knowledge and applicability to patient safety. Mayo Clin Proc 2010;85:53-62.

8. Ekman I, Swedberg K, Taft C, Lindseth A, Norberg A, Brink E, Carlsson J, DahlinIvanoff S, Johansson IL, Kjellgren K, Liden E, Ohlen J, Olsson LE, Rosen H, Rydmark M, Sunnerhagen KS. Person-centered care--ready for prime time. Eur J Cardiovasc Nurs $2011 ; 10: 248-251$.

9. Wallstrom S, Ekman I. Person-centred care in clinical assessment. Eur J Cardiovasc Nurs 2018; 17:576-579. 
10. Hakansson EJ, Holmstrom IK, Kumlin T, Kaminsky E, Skoglund K, Hoglander J, Sundler AJ, Conden E, Summer MM. "Same same or different?" A review of reviews of person-centered and patient-centered care. Patient Educ Couns 2019;102:3-11.

11. Santana MJ, Manalili K, Jolley RJ, Zelinsky S, Quan H, Lu M. How to practice personcentred care: a conceptual framework. Health Expect 2018;21:429-440.

12. Hall AE, Bryant J, Sanson-Fisher RW, Fradgley EA, Proietto AM, Roos I. Consumer input into health care: time for a new active and comprehensive model of consumer involvement. Health Expect 2018;21:707-713.

13. Sahlstrom M, Partanen P, Azimirad M, Selander T, Turunen H. Patient participation in patient safety-An exploration of promoting factors. J Nurs Manag 2019;27:84-92.

14. Ringdal M, Chaboyer W, Ulin K, Bucknall T, Oxelmark L. Patient preferences for participation in patient care and safety activities in hospitals. BMC Nurs 2017;16:69.

15. Tobiano G, Marshall A, Bucknall T, Chaboyer W. Patient participation in nursing care on medical wards: an integrative review. Int J Nurs Stud 2015;52:1107-1120.

16. van Dongen JJJ, Habets IGJ, Beurskens A, van Bokhoven MA. Successful participation of patients in interprofessional team meetings: a qualitative study. Health Expect 2017;20:724-733.

17. Oxelmark L, Ulin K, Chaboyer W, Bucknall T, Ringdal M. Registered Nurses' experiences of patient participation in hospital care: supporting and hindering factors patient participation in care. Scand J Caring Sci 2018;32:612-621.

18. Sohi J, Champagne M, Shidler S. Improving health care professionals' collaboration to facilitate patient participation in decisions regarding life-prolonging care: an action research project. J Interprof Care 2015;29:409-414. 
19. Larnebratt A, Fomichov V, Bjornsson B, Sandstrom P, Lindhoff LA, Drott J. Information is the key to successful participation for patients receiving surgery for upper gastrointestinal cancer. Eur J Cancer Care 2019;28:e12959.

20. Ibrahim F, Sandstrom P, Bjornsson B, Larsson AL, Drott J. 'I want to know why and need to be involved in my own care...': a qualitative interview study with liver, bile duct or pancreatic cancer patients about their experiences with involvement in care. Support Care Cancer 2019;27:2561-2567.

21. Arnetz JE, Hoglund AT, Arnetz BB, Winblad U. Staff views and behaviour regarding patient involvement in myocardial infarction care: development and evaluation of a questionnaire. Eur J Cardiovasc Nurs 2008;7:27-35.

22. Jamieson S. Likert scales: how to (ab)use them. Med Educ 2004;38:1217-1218.

23. Vargha A, Delaney HD. The Kruskal-Wallis test and stochastic homogeneity. J Educ Behav Stat 1998;23:170-192.

24. Sahlsten MJ, Larsson IE, Sjostrom B, Lindencrona CS, Plos KA. Patient participation in nursing care: towards a concept clarification from a nurse perspective. J Clin Nurs 2007;16:630-637.

25. Sherlock R, Wood F, Joseph-Williams N, Williams D, Hyam J, Sweetland H, McGarrigle H, Edwards A. "What would you recommend doctor?"-Discourse analysis of a moment of dissonance when sharing decisions in clinical consultations. Health Expect 2019;22:547-554.

26. Pii KH, Schou LH, Piil K, Jarden M. Current trends in patient and public involvement in cancer research: a systematic review. Health Expect 2019;22:3-20. 
27. Mavis B, Holmes RM, Jorgenson S, Coffey J, Anand N, Bulica E, Gaulden CM, Peacock J, Ernst A. Patient participation in clinical encounters: a systematic review to identify self-report measures. Health Expect 2015;18:1827-1843.

28. Blumenthal-Barby JS. 'That's the doctor's job': overcoming patient reluctance to be involved in medical decision making. Patient Educ Couns 2017;100:14-17.

29. Cook JV, Dickinson HO, Eccles MP. Response rates in postal surveys of health care professionals between 1996 and 2005: an observational study. BMC Health Serv Res 2009;9:160.

30. Angel S, Frederiksen KN. Challenges in achieving patient participation: a review of how patient participation is addressed in empirical studies. Int J Nurs Stud 2015;52:15251538.

31. Klaeson K, Hovlin L, Guva H, Kjellsdotter A. Sexual health in primary health care - a qualitative study of nurses' experiences. $J$ Clin Nurs 2017;26:1545-1554.

32. Vaismoradi M, Jordan S, Kangasniemi M. Patient participation in patient safety and nursing input - a systematic review. J Clin Nurs 2015;24:627-639.

33. Arnetz JE, Zhdanova L, Arnetz BB. Patient involvement: a new source of stress in health care work? Health Commun 2016;31:1566-1572.

34. Kolovos P, Kaitelidou D, Lemonidou C, Sachlas A, Zyga S, Sourtzi P. Patient participation in hospital care: nursing staffs' point of view. Int J Nurs Pract 2015;21:258268.

35. Andersson AC, Olheden A. Patient participation in quality improvement: managers' opinions of patients as resources. J Clin Nurs 2012;21:3590-3593. 
36. Nilsson M, From I, Lindwall L. The significance of patient participation in nursing care a concept analysis. Scand J Caring Sci 2019, 33: 244-251. 


\section{TABLES}

Table 1. Characteristics of questionnaire respondents $(n=102)$

\begin{tabular}{|c|c|c|c|}
\hline & $\begin{array}{c}\text { Physician } \\
\mathrm{n}(\%) \\
\mathrm{n}=24(23.5) \\
\end{array}$ & $\begin{array}{c}\text { Registered Nurse } \\
\mathrm{n}(\%) \\
\mathrm{n}=38(37.3)\end{array}$ & $\begin{array}{c}\text { Practical Nurse } \\
\mathrm{n}(\%) \\
\mathrm{n}=40(39.2)\end{array}$ \\
\hline \multicolumn{4}{|l|}{ Sex } \\
\hline Female & $6(25.0)$ & $27(71.1)$ & $32(80.0)$ \\
\hline Male & $18(75.0)$ & $11(28.9)$ & $8(20.0)$ \\
\hline \multicolumn{4}{|l|}{ Age } \\
\hline$\leq 29$ years old & $0(0.0)$ & $16(42.1)$ & $10(25.0)$ \\
\hline $30-39$ & $8(33.3)$ & $10(26.3)$ & $4(10.0)$ \\
\hline $40-49$ & $6(25.0)$ & $8(21.1)$ & $8(20.0)$ \\
\hline $50-59$ & $9(37.5)$ & $1(2.6)$ & $15(37.5)$ \\
\hline$\geq 60$ & $1(4.2)$ & $3(7.9)$ & $3(7.5)$ \\
\hline \multicolumn{4}{|c|}{ Years in the profession } \\
\hline $0-1$ years & $0(0.0)$ & $3(7.9)$ & $1(2.5)$ \\
\hline $1-5$ & $1(4.2)$ & $8(21.1)$ & $11(27.5)$ \\
\hline $5-10$ & $6(25.0)$ & $10(26.3)$ & $5(12.5)$ \\
\hline $10-15$ & $4(16.7)$ & $4(10.5)$ & $4(10.0)$ \\
\hline$\geq 15$ & $13(54.1)$ & $13(34.2)$ & $19(47.5)$ \\
\hline \multicolumn{4}{|c|}{ Years in the workplace } \\
\hline $0-1$ years & $2(8.3)$ & $11(28.9)$ & $12(30.0)$ \\
\hline $1-5$ & $10(41.7)$ & $13(34.2)$ & $16(40.0)$ \\
\hline $5-10$ & $1(4.2)$ & $2(5.3)$ & $0(0.0)$ \\
\hline $10-15$ & $5(20.8)$ & $4(10.5)$ & $7(17.5)$ \\
\hline$\geq 15$ & $6(25.0)$ & $8(21.1)$ & $5(12.5)$ \\
\hline
\end{tabular}


Table 2. Staff ratings of subscales: comparison between professions

\begin{tabular}{|c|c|c|c|c|c|}
\hline Subscale & $\begin{array}{c}\text { All } \\
\text { respondents } \\
\text { Median \% }\end{array}$ & $\begin{array}{l}\text { Physician } \\
\text { Median \% }\end{array}$ & $\begin{array}{l}\text { Registered } \\
\text { Nurse } \\
\text { Median \% }\end{array}$ & $\begin{array}{l}\text { Practical } \\
\text { Nurse } \\
\text { Median \% }\end{array}$ & p-value \\
\hline $\begin{array}{l}\text { Patient involvement }(\mathrm{n} \\
=97)\end{array}$ & 91.7 & 95.8 & 91.7 & 95.8 & ns \\
\hline Information $(\mathrm{n}=88)$ & 85.0 & 90.0 & 80.0 & 75.0 & 0.002 \\
\hline Patient needs $(n=94)$ & 81.3 & 87.5 & 81.3 & 81.3 & ns \\
\hline Activity $(\mathrm{n}=95)$ & 58.3 & 66.7 & 54.1 & 58.3 & 0.030 \\
\hline Motivation $(\mathrm{n}=95)$ & 70.8 & 87.5 & 70.8 & 54.1 & 0.001 \\
\hline Hindrance $(n=92)$ & 41.7 & 41.7 & 41.7 & 41.7 & ns \\
\hline
\end{tabular}


Table 3. Proportion of respondents who. to a very or fairly large extent. discussed with patients the following everyday activities

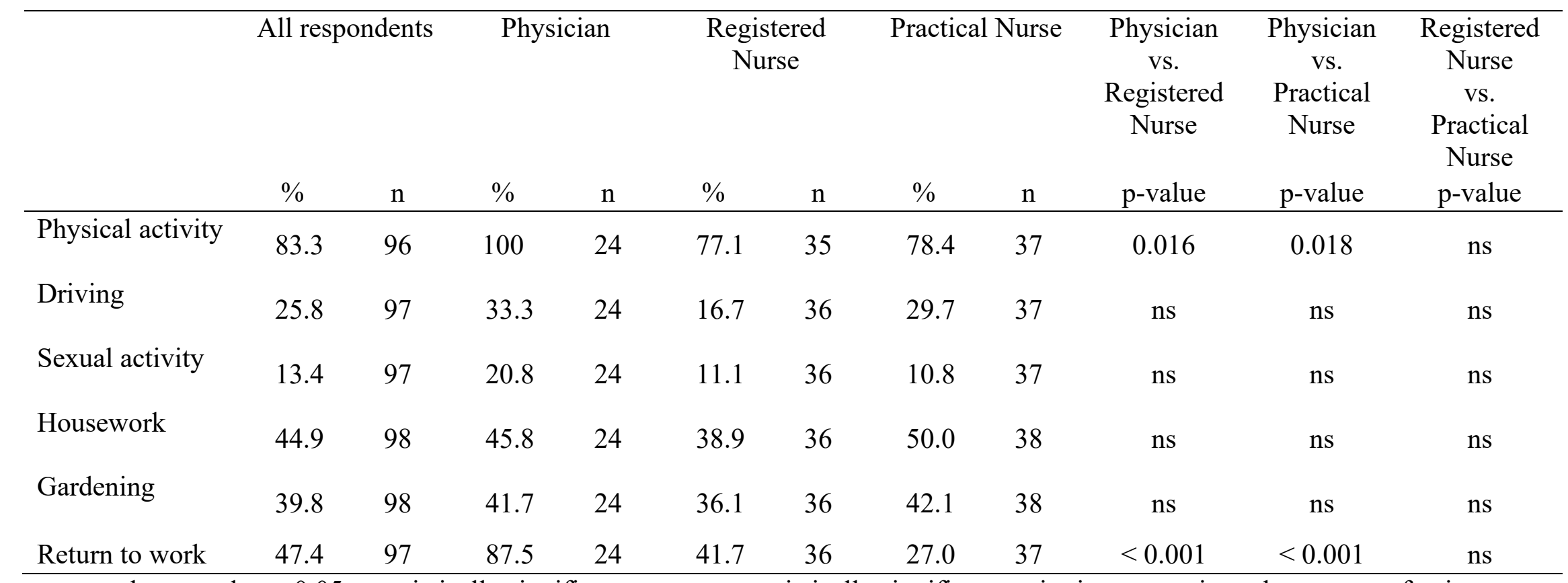

$\mathrm{n}=$ number, $\mathrm{p}$-value $<0.05=$ statistically significant, $\mathrm{ns}=$ non-statistically significant, pairwise comparisons between professions

(Fisher's exact test) 
Table 4. Proportions of respondents who either partially or to a high degree considered that the following factors prevent the possibility of conversing/supporting patients

\begin{tabular}{|c|c|c|c|c|c|c|c|c|c|c|c|}
\hline & $\begin{array}{r}A \\
\text { respo }\end{array}$ & ents & Phy & $\operatorname{ian}$ & Reg & red & Practic & Nurse & $\begin{array}{c}\text { Physician } \\
\text { vs. } \\
\text { Registered } \\
\text { Nurse } \\
\text { p-value }\end{array}$ & $\begin{array}{c}\text { Physician } \\
\text { vs. } \\
\text { Practical } \\
\text { Nurse } \\
\text { p-value }\end{array}$ & $\begin{array}{c}\text { Registerec } \\
\text { Nurse } \\
\text { vs. } \\
\text { Practical } \\
\text { Nurse } \\
\text { p-value }\end{array}$ \\
\hline Lack of time & 92.9 & 98 & 91.7 & 24 & 97.3 & 35 & 89.2 & 37 & ns & ns & ns \\
\hline $\begin{array}{l}\text { Prioritizing other } \\
\text { tasks }\end{array}$ & 93.9 & 99 & 91.7 & 24 & 100 & 36 & 89.5 & 37 & ns & ns & ns \\
\hline Patient does not want & 32.3 & 99 & 25.0 & 24 & 10.8 & 36 & 57.9 & 37 & ns & 0.018 & $<0.001$ \\
\hline Own uncertainty & 25.3 & 99 & 8.3 & 24 & 24.3 & 36 & 36.8 & 38 & ns & 0.017 & ns \\
\hline Culture & 58.2 & 98 & 54.2 & 24 & 55.6 & 36 & 63.2 & 38 & ns & ns & ns \\
\hline Relatives & 37.5 & 96 & 16.7 & 24 & 33.3 & 36 & 55.6 & 37 & ns & 0.003 & ns \\
\hline
\end{tabular}

$\mathrm{n}=$ number, $\mathrm{p}$-value $<0.05=$ statistically significant, $\mathrm{ns}=$ non-statistically significant, pairwise comparisons between professions

(Fisher's exact test) 


\section{FIGURE LEGENDS}

Figure 1. What does patient participation mean to you? $(\mathrm{n}=99)$. Presented in proportions $(\%)$. 
Healthcare professionals agree that the statement is related to the concept of patient participation

Healthcare professionals don't agree that the statement is related to the concept of patient participation

The patient gets clear information

The patient asks questions

The patient expresses his/her

views

The patient is involved in discussions about his/her care and treatment

The patient is involved in making decisions about his/her care and treatment

The patient bears the main responsibility for his/her future health

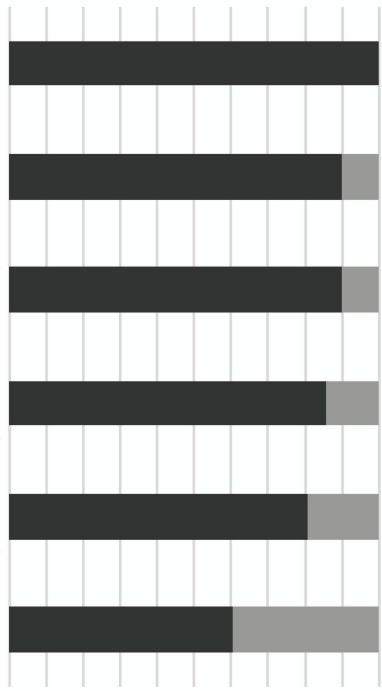

